\title{
Estudo Prospectivo sobre o Uso da Técnica de Biorremediação para a Recuperação de Solos Contaminados por Derivados do Petróleo
}

\section{Prospective Study About the Use of the Biormediation Technique for the Recovery of Contaminated Soil by Oil Derivatives}

\author{
Kamilla Costa de Sousa ${ }^{1}$ \\ José Edilson dos Santos Júnior ${ }^{1}$ \\ Vivianni Marques Leite dos Santos ${ }^{1}$ \\ ${ }^{1}$ Universidade Federal do Vale do São Francisco, Petrolina, PE, Brasil
}

\begin{abstract}
Resumo
Acidentes e vazamentos que envolvem produtos derivados de petróleo afetam bastante a natureza, pois o solo é fortemente prejudicado. Na busca por remediação, podem ser utilizados processos biológicos sobre a promissora relação custo/eficiência, com a devida consideração de fatores, como pH e umidade. Assim, este artigo tem como objetivo relatar os principais fatores envolvidos e os tipos de técnicas de biorremediação de solos contaminados por petróleo e seus derivados, bem como as principais iniciativas com geração de patentes. Foram identificadas seis famílias de patentes, com o primeiro pedido de proteção no Brasil, em 2007, pela Rhodia Poliamida \& Especialidades, detendo a maior família de patentes depositadas em sete organizações ou países. É do Brasil a patente para um dispositivo móvel, concedida para o Instituto de Pesquisas Tecnológicas do Estado de São Paulo. Ao final, conclui-se pela viabilidade de aplicação da técnica e pela possibilidade de inovações incrementais.
\end{abstract}

Palavras-chaves: Contaminação. Impactos Ambientais. Recuperação de Solo. Sustentabilidade.

\begin{abstract}
Accidents and leaks involving petroleum products greatly affect the environment and the soil is severely damaged. In the search for remediation, biological processes can be used due to promising cost/efficiency ratio, with due consideration of factors such as $\mathrm{pH}$ and humidity. Thus, this article aims to report the main factors involved and the types of bioremediation techniques of soils contaminated by oil and its derivatives, as well as the main initiatives with patent generation. Six patent families were identified, with the first application for protection, in Brazil, in 2007, by Rhodia Poliamida \& Especialidades, holding the largest patent family deposited in 7 organizations or countries. It is from Brazil the patent for a mobile device, granted for the Institute of Technological Research of the State of São Paulo. In the end, it concludes by the feasibility of applying the technique and the possibility of incremental innovations.
\end{abstract}

Keywords: Contamination. Environmental Impacts. Soil Recuperation. Sustainability.

Área Tecnológica: Inovação. Prospecção Tecnológica e Desenvolvimento. 


\section{Introdução}

Diante do processo de industrialização iniciado em meados do século XVIII, os produtos estão cada vez mais avançados. Porém, junto a isso, inúmeros problemas relacionados à poluição ambiental se acentuaram, sendo verificados principalmente devido ao aumento da poluição $e$ da produção de resíduos. Assim, surge a necessidade de investimentos e de implementação de técnicas de remedição desses prejuízos (RIZZO et al., 2007).

O solo é um recurso natural de grande importância para os ecossistemas e ciclos naturais. No entanto, a disponibilidade desse recurso pode ser comprometida devido às atividades humanas inerentes ao desenvolvimento socioambiental, quando ocorre sem comprometimento com a preservação ambiental (RIZZO et al., 2007). Os autores citam ainda que uma forma de ocorrer a degradação do solo pode ser por meio da desertificação, pelo uso de tecnologias inadequadas, pela ausência de conservação ou pela destruição da vegetação, seja por meio de desmatamento ou queimadas (RIZZO et al., 2007).

Por outro lado, o processo de contaminação do solo e do subsolo ocorre na deposição, disposição, descarga, infiltração, acumulação, injeção ou aterramento de produtos poluentes que se encontram em estado sólido, líquido ou gasoso. Assim, essa contaminação acontecerá sempre que ocorrer adição de compostos que alteram as características naturais do solo e as suas funcionalidades, produzindo assim impactos negativos ao mesmo (RIZZO et al., 2007).

No âmbito industrial, destaca-se o setor do petróleo como exemplo altamente utilizado como fonte de energia. É um dos principais vilões do meio ambiente, sendo base para a produção de variados produtos, entre eles: lubrificantes, óleo diesel, querosene, asfaltos e cosméticos (CARNEIRO; CARIGLIO, 2010).

Devido aos casos de derramamento de óleo em postos de combustíveis, surge a preocupação de esse óleo vazado atingir as águas subterrâneas, que são usadas para consumo humano. Em contato com o solo, o combustível se separa em três fases: líquida, gasosa e dissolvida. Quando partículas dos componentes se diluem no lençol freático, uma porção é retida no solo e outra é evaporada, ocorrendo então à poluição atmosférica (MARIANO, 2006).

Notou-se que poucos organismos conseguem se adaptar a ambientes contaminados pelo petróleo e seus derivados. Nesse contexto, existem algumas técnicas que permitem recuperar ou remediar o meio contaminado. Entre as quais destaca-se a biorremediação, que consiste em degradar resíduos prejudiciais ao ambiente com a utilização de microrganismos, sendo capaz de reverter os danos causados pela contaminação.

Assim, no sentido de contribuir para busca de soluções para esse problema altamente poluidor, este artigo descreve as principais técnicas utilizadas no processo de biorremediação do petróleo e seus derivados, destacando os principais microrganismos envolvidos e discorrendo sobre as vantagens e as desvantagens da utilização dessa tecnologia, bem como mapeando as tecnologias com solicitação de proteção para viabilizar estudos acerca de novos desenvolvimentos. 


\section{Metodologia}

Este artigo é caracterizado como um estudo bibliográfico (GIL, 2017), já que seu desenvolvimento está constituído, principalmente, de relatos a partir de pesquisas em livros, artigos científicos e tecnologias com solicitação de patentes.

Quanto à natureza da pesquisa, de acordo com Nascimento e Sousa (2016), este artigo se caracteriza sob o enfoque da natureza de pesquisa aplicada, que pretende gerir conhecimento para solucionar problemas específicos, determinando aplicação prática em situação particular.

Com relação à abordagem, esta pesquisa é caracterizada como pesquisa quanti-qualitativa (MICHEL, 2009), sendo fundamentada na análise de dados numéricos com suficiência descritiva, além da análise qualitativa, realizada de forma aprofundada, descritiva e explicativa sobre as tecnologias já desenvolvidas dentro da temática.

Nesse contexto, trata-se de uma pesquisa descritiva quanto aos objetivos que tem como intuito descrever as características de determinada população e/ou fenômeno estabelecendo relações entre as variáveis (GIL, 2017). Neste estudo, caracteriza-se a descrição dos principais aspectos relacionados à técnica de biorremediação para a recuperação de solos contaminados por derivados do petróleo.

Como estratégias e fases da pesquisa, este trabalho foi realizado da seguinte da forma:

a) Levantamento teórico/tecnológico: foram utilizados artigos, livros, sites de busca da Capes, Scielo e acesso aos bancos de dados de patentes por meio do Questel Orbit, estabelecendo o embasamento teórico e o estado da técnica, essenciais para desenvolvimento de novas técnicas. Foram utilizadas as palavras-chave "biorremediação e solo" (e bioremediation and soil), inicialmente, sendo verificados termos adicionais identificados a partir da busca na literatura, referentes aos tipos de biorremediação descritos no item de resultados. A busca foi feita no título e no resumo das patentes.

b) Análise do material teórico: os conteúdos teóricos a partir de artigos foram analisados de modo a explorar os estudos mais detalhados e embasados sobre o tema abordado, de modo que os artigos e patentes foram selecionados com extração dos aspectos mais importantes, ou seja: tipo de contaminação do solo; técnica de biorremediação; domínio das tecnologias; status legal das patentes; principais pesquisadores/inventores e principais empresas envolvidas nos desenvolvimentos.

\section{Resultados e Discussão}

Com base nos principais componentes dos derivados do petróleo e seus impactos, foram realizadas pesquisas sobre os principais tipos de biorremediação para planejamento e decisões durante a busca pelo estado da técnica em termos de desenvolvimentos tecnológicos, tomando como base a descrição dada por Cunha (2008) sobre a técnica de biorremediação, que destaca o princípio da utilização de populações microbianas com habilidades para decompor poluentes, promovendo a degradação total ou atingindo valores abaixo daqueles estabelecidos pelas agências regulamentadoras. 
Para fundamentação teórica acerca da técnica, Rizzo et al. (2007) destacam a necessidade de condições ambientais adequadas para que o processo ocorra de forma eficaz, pois, em caso contrário, a biorremediação dos poluentes ficará comprometida. Weber e Santos (2013) apontam que a biorremediação é mais eficiente e menos onerosa para despoluição de solos quando comparada aos processos de incineração, lavagem e aterro. Segundo Weber e Santos (2013), os tipos de biorremediação são:

a) Biorremediação bioestimuladora ou atenuação natural acelerada: ocorre por meio da adição de fertilizantes como nitrogênio e fósforo em locais contaminados, pois estes estimulam o processo de degradação das substâncias tóxicas existentes em diferentes ambientes.

b) Bioventilação: é uma tecnologia in situ na qual se adiciona oxigênio ao solo contaminado para favorecer o crescimento, desenvolvimento e metabolização de microrganismos. Essa técnica é efetiva para remediar danos causados por derivados do petróleo, como gasolina, querosene e diesel.

c) Bioaumentação: é uma técnica recente em que os microrganismos são inoculados em ambientes contaminados que metabolizam meios que contêm substâncias tóxicas ou bactérias geneticamente modificadas para decompor produtos derivados de petróleo.

d) Biopilhas: é um tratamento ex situ. O material contaminado é armazenado em biopilhas. Primeiro escava-se o solo, depois coloca-se em biopilhas, pois esses microrganismos são estimulados a metabolizar componentes do petróleo, por meio da aeração, adição de nutrientes e aumento da umidade do solo.

e) Air Sparging: é uma técnica em que introduz ar no aquífero contaminado com a intenção de produzir borbulhas na água. Essas bolhas de ar atravessam o solo, criando uma aeração que remove os componentes por meio da volatização.

f) Landfarming: é uma tecnologia que se dá por meio da biodegradação, na qual ocorre a redução de concentrações dos elementos do petróleo.

g) A mais tradicionalmente conhecida, Compostagem: é um método que degrada os resíduos oleosos oriundos de refino de petróleo. Nesse processo, os resíduos são envolvidos no solo e sujeitos à bioestimulação.

Por outro lado, com base no levantamento realizado, de acordo com Reginatto, Colla e Thomé (2011), os fatores ambientais que interferem no processo de biorremediação são:

a) Aeração: são necessárias condições aeróbias para que a biodegradação de hidrocarbonetos de petróleo ocorra de forma rápida, uma vez que a degradação anaeróbica desses compostos é extremamente lenta.

b) Nutrientes: para os microrganismos sobreviverem, eles precisam de fontes de nutrientes. Nitrogênio fósforo e potássio são os principais nutrientes inorgânicos inseridos, quando necessários, nesse processo.

c) Umidade: durante o processo, esse teor deve ser mantido entre 50-80\% da capacidade do solo para que a degradação do solo ocorra da melhor forma possível. Umidade reduzida afeta negativamente o metabolismo microbiano, enquanto o teor excessivo limita o fluxo de oxigênio no solo. 
d) Agitação: os microrganismos não se dispersam facilmente no solo. Sendo o movimento importante para que os microrganismos atinjam locais em que nutrientes contaminantes e outros microrganismos estejam incorporados.

e) pH: a técnica é extremamente dependente do meio envolvido, sendo que, em pH neutro, a biodegradação é mais efetiva.

f) Temperatura: relacionada entre a quantidade de energia calorífica absorvida e perdida. Esse fator é de grande importância, pois temperaturas baixas controlam o transporte de nutrientes e temperaturas altas ocasionam taxas de biodegradação mais rápidas.

\subsection{Principais Desenvolvimentos Tecnológicos}

Entre os principais desenvolvimentos tecnológicos, foram identificadas seis famílias de patentes (cada família de patentes refere-se a uma mesma invenção depositada em diferentes países) depositadas com uso das palavras-chave biorremediação e solo (e bioremediation and soil), nos títulos ou nos resumos, sendo uma delas concedida, três pendentes e duas inativas ou mortas, todas no domínio de tecnologias ambientais (Figura 1) e publicadas a partir do ano de 2002 (Figura 2). Todas as patentes foram depositadas no Brasil, o que se considera uma informação interessante no contexto do desenvolvimento da técnica no mundo.

Os outros domínios da tecnologia nos quais se encaixam as patentes referem-se à química de materiais e aos métodos de gerenciamento, que se remetem às ações necessárias para biorremediação, em geral, e partem de planejamentos em programas de gerenciamento ambiental, e, por fim, no domínio de outras máquinas especiais. Esta última se refere a um modelo de utilidade desenvolvido por Maximiniano et al. (2012), cuja patente concedida em janeiro de 2019 será citada mais adiante neste estudo.

Um aspecto relevante é que o primeiro depósito foi realizado pela Petrobrás (QUESTEL ORBIT INTELIGENCE, 2019), com Sant'anna como inventor, pelo desenvolvimento de um biorreator horizontal e o processo de biorremediação, para ser utilizado em processos ex situ, em descontaminação de solo argiloso contaminado com hidrocarbonetos, cujos componentes e conexões foram devidamente descritos (SANT'ANNA, 2002).

Figura 1 - Patentes por domínios de tecnologias

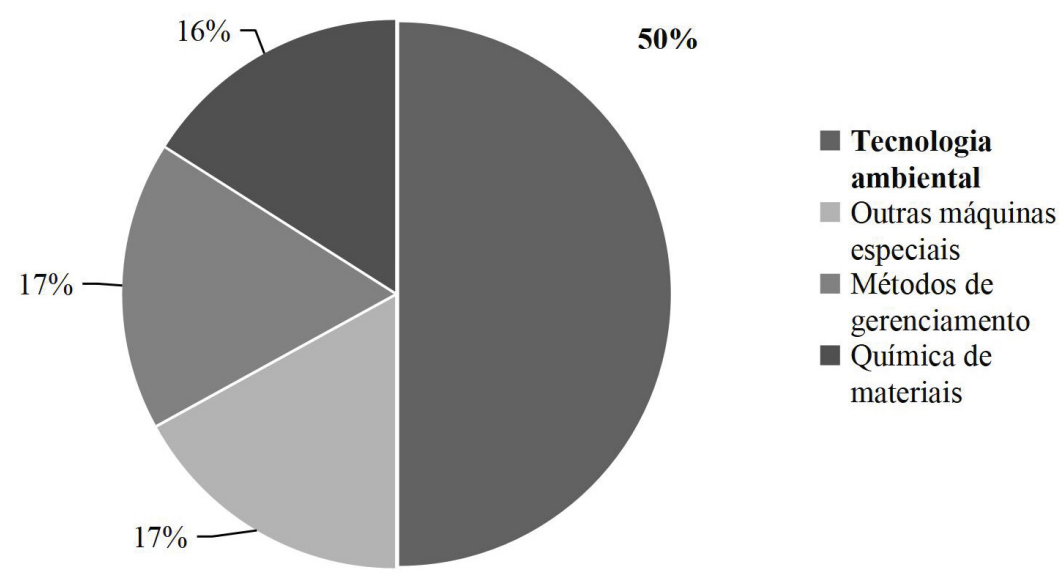

Fonte: Elaborada pelos autores deste artigo a partir de dados obtidos por meio do Questel Orbit Inteligence (2019) 
Figura 2 - Número de famílias de patentes por ano do primeiro depósito

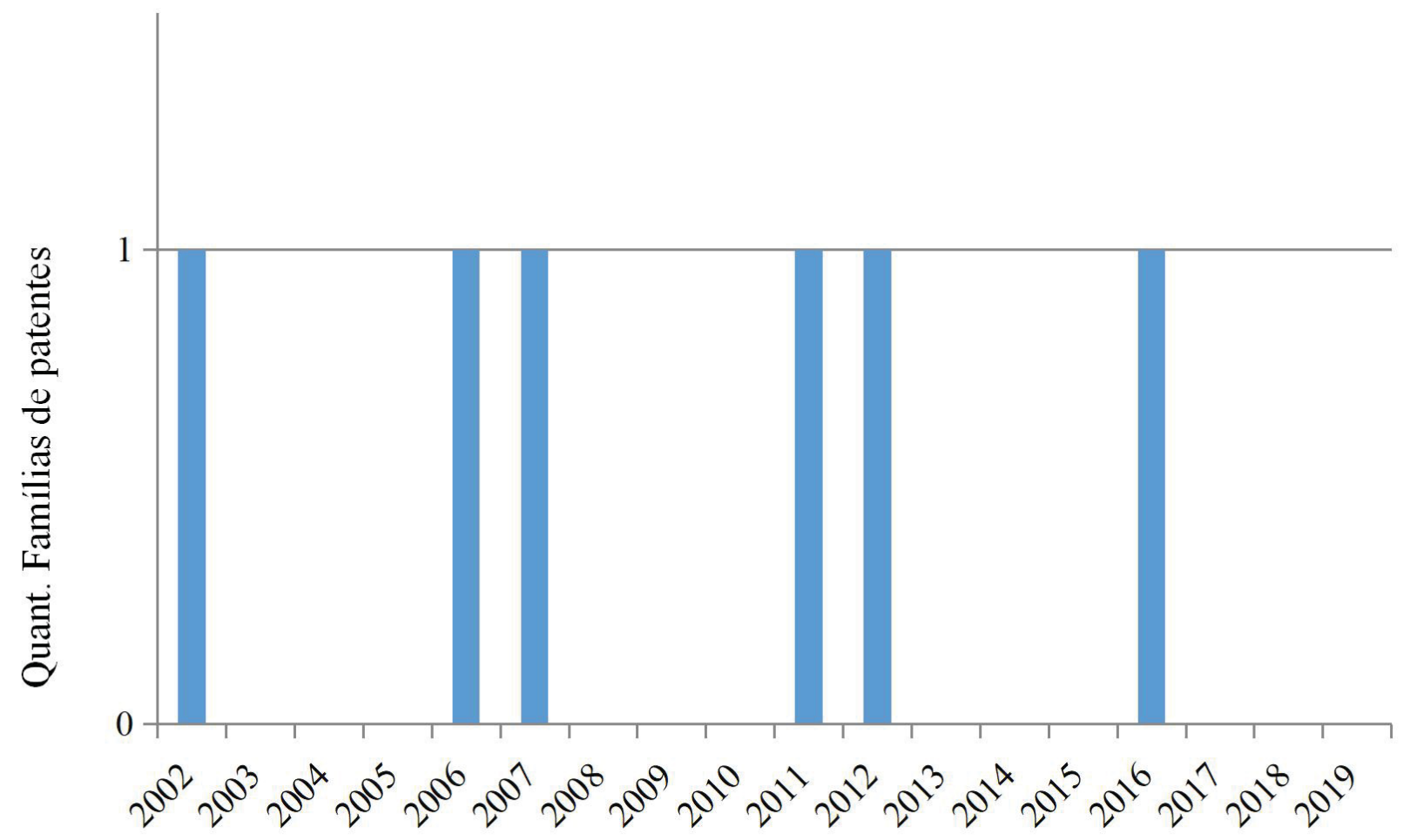

Fonte: Elaborada pelos autores deste artigo a partir de dados obtidos por meio do Questel Orbit Inteligence (2019)

Com relação ao número de depósito por país, verifica-se um maior número no Brasil (6), seguido pelos Estados Unidos (4) e apenas um depósito, pela Rhodia Poliamida \& Especialidades, no Canadá, China, Escritório europeu, República da Coreia e Organização Mundial da Propriedade Intelectual (OMPI) (QUESTEL ORBIT INTELIGENCE, 2019).

Destaca-se que a maior família de patentes, ou seja, uma mesma invenção com entrada de pedido de proteção em países distintos, foi depositada em sete organizações ou países. Trata-se da patente depositada, prioritariamente, no ano de 2007, pela Rhodia Poliamida \& Especialidades, com proposição de um método para a biorremediação de solo contaminado por compostos orgânicos e/ou inorgânicos por meio da adição de um substrato natural e também um método para biorremediação de águas superficiais ou subterrâneas contaminadas por aqueles compostos (orgânicos e/ou inorgânicos) (MORETTI et al., 2007).

Maximiniano et al. (2012), do Instituto de Pesquisas Tecnológicas do Estado de São Paulo, desenvolveram uma unidade piloto industrial, como modelo de utilidade para tratamento pela injeção de produtos químicos oxidantes no solo e/ou água subterrânea. O referido modelo foi proposto em 2012 com a vantagem de constituir unidade móvel para remediação do solo e águas subterrâneas (Figura 3), formado pelos seguintes componentes: (B) Suporte para a estrutura; (C) Mistura de compostos oxidantes; (D) Reservatório de água; Local onde ocorre a decomposição por injeção de oxidantes; (F) Sistema para a suspensão de ferro; (G) Plataforma de acesso; (G) Sistema gerador; (G) Sistema de acesso; (3) e (4) Sistema para economia de energia; e (5) Sistema injetável. 
Figura 3 - Desenho esquemático do modelo de utilidade, unidade industrial em perspectiva, para tratamento de solo e água subterrânea

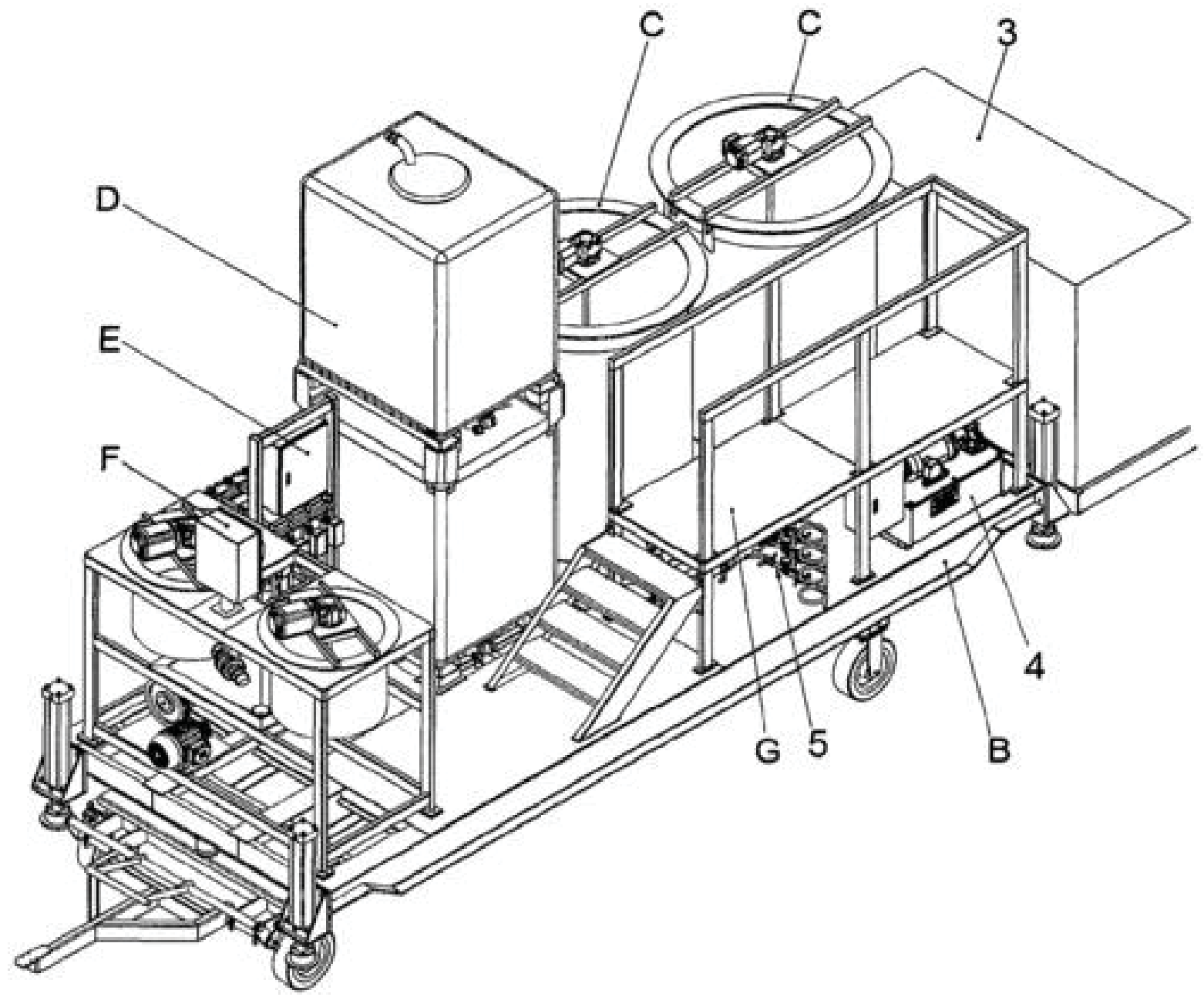

Fonte: Maximiliano et al. (2012)

De acordo com os autores, a unidade também pode ser usada para biorremediação, por meio de tratamento biológico de contaminantes, cuja solução biológica pode ser preparada em um módulo de tratamento adicionado ao sistema (MAXIMILIANO et al., 2012). O módulo de tratamento pode também ser usado para aeração pela adição de oxigênio ou outro para oferecer um ambiente aeróbico aos micro-organismos. Além da remediação do solo, destaca-se a possibilidade de uso na agricultura, por exemplo, para injeção de fertilizantes e outros componentes que enriquecem o solo. Essa invenção foi desenvolvida no Instituto de Pesquisas Tecnológicas do Estado de São Paulo (IPT) e gerou 220 patentes desde o ano de 1999.

Em 2016, a BEIFIUR, por meio de Siqueira, desenvolveu processo e sistema de compostagem estático com umidificação e extração/recirculação de líquidos, aplicável à compostagem de resíduos orgânicos e/ou minerais para a produção de fertilizantes orgânicos e/ou organominerais de alta tecnologia, podendo ser utilizado na agricultura, na recomposição de solos e na biorremediação de solos contaminados. Destacou aumento da matéria húmica pelo controle da recirculação de extrato maturado e de nutrientes disponíveis pela inserção programada de nutrientes orgânicos sustentáveis nas fases de compostagem, além da eliminação de microrganismos patogênicos (SIQUEIRA, 2016). 
Outra análise relevante está na identificação da categorização IPC (Figura 4), uma vez que pode constituir uma alternativa para identificar possíveis novos usos para as referidas patentes. No caso em particular, duas patentes estão classificadas na área de recuperação de solos contaminados.

Figura 4 - Famílias de patentes por classificação IPC principal

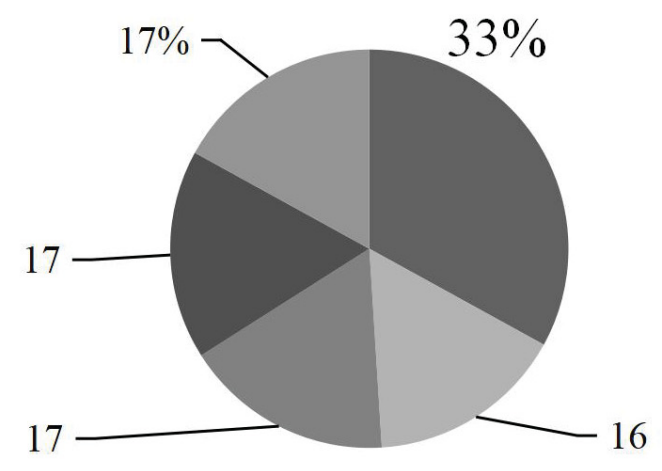

\author{
B09C-001 - Recuperação \\ de solo contaminado \\ A01B-051 - Carrinhos \\ transportadores adaptados \\ para serem neles montados \\ diversos tipos de \\ implementos ou aparelhos
}

Fonte: Elaborada pelos autores deste artigo a partir de dados obtidos por meio do Questel Orbit Inteligence (2019)

Com base no estudo teórico a partir de artigos científicos que permitiu identificação dos diferentes tipos de biorremediação (WEBER; SANTOS, 2013), foram também efetuadas buscas com os termos biaumentação e solo; bioventilação e solo; biopinhas e solo; Air Sparging; Landfarming e compostagem. Verificou-se que não há publicação de patentes para uso da técnica de biorremediação com utilização dos termos citados. No caso da compostagem, foram identificadas 20 patentes, mas não tratavam da descontaminação do solo ou da água.

\title{
4 Considerações Finais
}

Os solos contaminados por petróleos são importantes áreas a serem estudadas, devido aos vazamentos e aos derramamentos constantes ocorridos por diferentes razões. Entre as técnicas que podem ser aplicadas para reverter essa situação, a biorremediação é uma das mais utilizadas em função do baixo custo em relação a tecnologias já desenvolvidas para esse fim. Como todos os solos já possuem certa quantidade de microrganismos, essa técnica pode se sobressair entre as demais.

Para que os microrganismos realizem a degradação do petróleo e seus derivados no solo, alguns fatores ambientais são fundamentais para a eficiência do método e devem ser criteriosamente analisados, que são: a aeração, a umidade, o pH, a agitação, a temperatura e os nutrientes presentes no solo, portanto, são parâmetros que devem ser levados em consideração nos diversos estudos para proposição de métodos e/ou máquinas.

Para desenvolvimento ou uso adequado de sistema para descontaminação do solo, devem ser verificadas mais detalhadamente as invenções citadas neste estudo, protegidas por meio de patentes. Isso é necessário para evitar desenvolvimento de algo que já existe com perdas de investimentos ou prejuízos por uso não permitido por titulares de patentes. 
Verificou-se que, apesar das promissoras vantagens associadas à técnica, há poucos desenvolvimentos na área, já que foram encontradas apenas seis famílias, ou documentos, de patentes. Por outro lado, um fator observado foi a atuação do Brasil frente a essa tecnologia.

A Rhodia Poliamida \& Especialidades destaca-se com pedido de proteção em maior número de países para uma patente na área, a qual foi depositada em sete organizações ou países, com primeiro país de depósito no ano de 2007, segundo a qual se propõe um método para a biorremediação de solo contaminado por compostos orgânicos e/ou inorgânicos por meio da adição de um substrato natural e também um método para biorremediação de águas superficiais ou subterrâneas contaminadas por aqueles compostos.

Como patente concedida, destaca-se aquela desenvolvida pelo Instituto de Pesquisas Tecnológicas do Estado de São Paulo, com a proposta de uma unidade piloto industrial móvel, como modelo de utilidade para tratamento pela injeção de produtos químicos oxidantes no solo e/ou água subterrânea.

Isso posto, já existem tecnologias disponíveis para descontaminação do solo por derivados do petróleo, já que pode ser analisada a viabilidade de aplicação e inovações incrementais no que se refere a novos compostos naturais mais amigáveis ao meio ambiente ou dispositivos com rendimento ou eficiência melhorada ou ainda adaptações às demandas específicas devido aos diferentes tipos de solos e níveis de contaminação.

\section{Referências}

CARNEIRO, D. A.; CARIGLIO, L. P. A biorremediação como ferramenta para a descontaminação de ambientes terrestres e aquáticos. Revista Tecer, Belo Horizonte, v. 3, n. 4, 2010.

CORREAA, O. L. S. Petróleo: noções sobre exploração, perfuração, produção e microbiologia. Rio de Janeiro: Ed. Interciência, 2003.

CUNHA, C. D. da. Biorremediação de Água Subterrânea Contaminada com Gasolina e Análise Molecular da Comunidade Bacteriana Presente. Rio de Janeiro: CETEM/MCT. 2008. 45p.

GIL, A. C. Como Elaborar Projetos de Pesquisa. 6. ed. São Paulo: Atlas, 2017.

MARIANO, A. P. Avaliação do Potencial de Biorremediação de Solos e de Água Subterrâneas Contaminados com Óleo Diesel. Rio Claro: [s.n.], 2006. 162p.

MAXIMIANO, A. M. de S. et al. Small industrial unit for the treatment and injection of oxidant and ground-related oxidizing chemicals and groundwater. Depositada em 30/11/2012.

MICHEL, M. H. Metodologia e Pesquisa Científica em Ciências Sociais. 2. ed. São Paulo: Atlas, 2009.

MORETTI, J. C. et al. Method for the bioremediation of soil and/or water contaminated by organic and/or inorganic compounds. Depositada em 05/09/2007.

NASCIMENTO, F. P. do; SOUSA, Flávio Luís Leite. Metodologia da Pesquisa Científica. 2. ed. Fortaleza: INESP, 2016. 
QUESTEL ORBIT INTELIGENCE. [Ferramenta de busca de bases de dados-Internet].

(C) Questel;2018. Disponível em: www.orbit.com. Acesso em: 2 jul. 2019.

REGINATTO, C.; COLLA, L. M.; THOMÉ, A. Biorremediação de resíduos oleosos em solo. Passo Fundo: CIATEC-UPF, 2011. v. 3. p. 19-31.

RIZZO, A. C. de L. et al. Biorremediação de solos contaminados por petróleos: ênfase no uso de biorreatores. Rio de Janeiro: CETEM/MCT. 2007. 76p.

SANT'ANNA, A. C. C. M. Horizontal biorreator and process of biorremediacao of argillaceous ground using said biorreator. Depositada em 12/04/2002.

SIQUEIRA, O. P. Process and static system of composting with umidificaçao and extraçao/ recirculaçao of liquids. Depositada em 21/06/2016.

WEBER, B. D.; SANTOS, A. A. Utilização da Biorremediação como Ferramenta para o Controle da Degradação Ambiental Causada pelo Petróleo e seus Derivados. Espírito Santo do Pinhal. 2013. v. 10. p. 114-133.

\section{Sobre os Autores}

\section{Kamilla Costa de Sousa}

E-mail: kamillacosta.2014@gmail.com

Graduanda de Engenharia de Produção.

Endereço profissional: Universidade Federal do Vale do São Francisco, Campus Juazeiro, BA, Curso de Engenharia de Produção, Av. Antônio Carlos Magalhães, n. 510, Bairro Country Club, Juazeiro, BA. CEP: 48902-300.

\section{José Edilson dos Santos Júnior}

E-mail: edilsonsjr@gmail.com

Especialista em Saneamento e Gestão Ambiental.

Endereço profissional: Universidade Federal do Vale do São Francisco, Campus Petrolina, PE, Prefeitura Universitária, Av. José de Sá Maniçoba, s/n, Bairro Centro, Petrolina, PE. CEP: 56304-205.

\section{Vivianni Marques Leite dos Santos}

E-mail: vivianni.santos@gmail.com

Doutora em Química.

Endereço profissional: Universidade Federal do Vale do São Francisco, Campus Juazeiro, Colegiado do Programa de Pós-Graduação em Propriedade Intelectual e Transferência de Tecnologia, Av. Antônio Carlos Magalhães, n. 510, Bairro Country Club, Juazeiro, BA. CEP: 48902-300. 